\title{
Article \\ MiR-181a-5p Regulates NIS Expression in Papillary Thyroid Carcinoma
}

\author{
Wojciech Gierlikowski ${ }^{1} * \mathbb{\oplus}$, Katarzyna Broniarek ${ }^{2} \oplus$, tukasz Cheda $^{3}{ }^{\text {, Zbigniew Rogulski }}{ }^{3}$ \\ and Marta Kotlarek-Łysakowska ${ }^{4}$ \\ 1 Department of Internal Medicine and Endocrinology, Medical University of Warsaw, Banacha 1a, \\ 02-097 Warsaw, Poland \\ 2 Faculty of Medicine, Medical University of Warsaw, Żwirki i Wigury 61, 02-091 Warsaw, Poland; \\ broniarekkatarzyna@gmail.com \\ 3 Faculty of Chemistry, Biological and Chemical Research Centre, University of Warsaw, Żwirki i Wigury 101, \\ 02-089 Warsaw, Poland; lcheda@chem.uw.edu.pl (Ł.C.); rogul@chem.uw.edu.pl (Z.R.) \\ 4 Warsaw Genomics, Żwirki i Wigury 101, 02-089 Warsaw, Poland; \\ marta.kotlarek-lysakowska@warsawgenomics.pl \\ * Correspondence: wgierlikowski@wum.edu.pl
}

Citation: Gierlikowski, W.;

Broniarek, K.; Cheda, Ł.; Rogulski, Z.; Kotlarek-Łysakowska, M.

MiR-181a-5p Regulates NIS

Expression in Papillary Thyroid

Carcinoma. Int. J. Mol. Sci. 2021, 22,

6067. https://doi.org/10.3390/

ijms22116067

Received: 10 April 2021

Accepted: 1 June 2021

Published: 4 June 2021

Publisher's Note: MDPI stays neutra with regard to jurisdictional claims in published maps and institutional affiliations.

Copyright: (c) 2021 by the authors. Licensee MDPI, Basel, Switzerland. This article is an open access article distributed under the terms and conditions of the Creative Commons Attribution (CC BY) license (https:// creativecommons.org/licenses/by/ $4.0 /)$.

\begin{abstract}
NIS is a potent iodide transporter encoded by the SLC5A5 gene. Its expression is reduced in papillary thyroid carcinoma (PTC). In this study we analyzed the impact of miR-181a-5p on NIS expression in the context of PTC. We used real-time PCR to analyze the expression of SLC5A5 and miR181a-5p in 49 PTC/normal tissue pairs. Luciferase assays and mutagenesis were performed to confirm direct binding of miR-181a-5p to the $3^{\prime}$ UTR of SLC5A5 and identify the binding site. The impact of modulation of miR-181a-5p using appropriate plasmids on endogenous NIS and radioactive iodine accumulation was verified. We confirmed downregulation of SLC5A5 and concomitant upregulation of miR-181a-5p in PTC. Broadly used algorithms did not predict the binding site of miR-181a-5p in $3^{\prime}$ UTR of SLC5A5, but we identified and confirmed the binding site through mutagenesis using luciferase assays. In MCF7 and HEK293-flhNIS cell lines, transfection with mir-181a-expressing plasmid decreased endogenous SLC5A5, whereas silencing of miR-181a-5p increased it. We observed similar tendencies in protein expression and radioactive iodine accumulation. This study shows for the first time that miR-181a-5p directly regulates SLC5A5 expression in the context of PTC and may decrease efficacy of radioiodine treatment. Accordingly, miR-181a-5p may serve as an emerging target to enhance the efficacy of radioactive iodine therapy.
\end{abstract}

Keywords: NIS; SLC5A5; microRNA; miR-181a-5p; papillary thyroid carcinoma; thyroid carcinoma; PTC

\section{Introduction}

The ability of the thyroid gland to accumulate iodide has been known since the end of the 19th century [1]. Diagnostic use of radioiodine dates back to the 1930s [2], and since the 1940s radioiodine has been used for the treatment of thyroid carcinoma [3]. The capability of thyroid to collect iodide, necessary for fulfilling its physiological function, which is synthesis of iodine-containing thyroxin and triiodothyronine [4], results from the activity of mainly one protein-sodium/iodide symporter (NIS). NIS is a multi-pass membrane glycoprotein located on the basolateral membrane of thyroid follicular epithelial cells, which is able to concentrate iodine, creating an up to 40-fold gradient [5]. It consists of 643 amino acids and is encoded by the SLC5A5 gene [6]. Soon after its molecular characterization, it was found that expression of NIS is reduced in thyroid tumors compared to normal thyroid tissue [7].

Thyroid carcinoma is the most common endocrine malignancy, and its incidence is rising. Papillary thyroid carcinoma (PTC) comprises about $85 \%$ of the cases [8]. Genetics of 
PTC was characterized as a part of The Cancer Genome Atlas (TCGA) project, revealing generally low somatic mutation density, with mainly MAPK-related genes (i.e., BRAF, NRAS, HRAS and KRAS) [9]. The presence of the BRAFV600E mutation, occurring in approximately $50 \%$ of PTC [10], leads to NIS repression by TGF $\beta$ pathway [11,12], decreases its expression by promotor deacetylation [13] and disrupts its trafficking to cell membranes [14].

MicroRNAs (miRNAs, miRs) are short (19-25 nucleotides) non-coding RNA molecules that usually function as inhibitors of the expression of protein-coding genes. Previous reports suggest that microRNAs altogether regulate around $60 \%$ of the human genome [15]. Mature microRNAs bind to complementary sequences in mRNA $3^{\prime}$ untranslated regions ( $3^{\prime}$ UTRs), thus inhibiting translation or promoting mRNA degradation [16]. Many cancers, including PTC, exhibit aberrant expression of microRNAs [17], which leads to deregulation of expression of numerous protein-coding genes.

Changes in microRNA expression patterns are typical for different pathological conditions and can be used to diagnose thyroid lesions (as revised in [18]). Aberrant expression of microRNAs leads to altered expression of their target genes, contributing to promotion and progression of cancer. Since the expression of microRNAs can be modulated, this phenomenon can be further used for the tailoring of adjuvant cancer therapies [19].

So far, it has been reported that NIS is regulated by miR-146a-3p [20], miR-146b3p [21,22], miR-339-5p [23] and miR-875-5p [24].

During our previous work, we noticed that miR-181a-5p targets the apical iodine transporter (AIT, encoded by SLC5A8) [25] and was predicted to regulate pendrin by in silico analyses. Consequently, we expected that overexpression of miR-181a5p would have led to increased radioiodine retention, whereas silencing, to decreased radioiodine retention. As the results were contrary to expected, we hypothesized that miR-181a-5p regulates NIS as well and performed the present study, aiming to test this hypothesis.

\section{Results}

2.1. The Expression of SLC5A5 Is Lowered in PTC

The samples consisted of two groups: cancer tissue $(n=49$, PTC-T) and control tissue (paired normal tissue from the same patient; $n=49$, PTC-N). The patients represented all stages of the disease excluding IVB; $44(90 \%)$ tumors represented the classic variant of PTC (PTCcv) and $5(10 \%)$ were the follicular variant of PTC (PTCfv). The medium tumor diameter was $16.23 \mathrm{~mm}$ (range: 1-73 mm). Patient characteristics are summarized in Table 1. $\mathrm{BRAF}^{\mathrm{V} 600 \mathrm{E}}$ mutation status was checked as described previously [17] in 41/49 tumors, identifying the mutation in 18 of them.

In $43 / 49(87 \%)$ tissue pairs, the expression of SLC5A5 was lower in tumor than in control tissue. The median decrease in the whole group was 12.27 -fold $(p<0.0001)$. The difference was significant regardless of $\mathrm{BRAF}^{\mathrm{V} 600 \mathrm{E}}$ status ( $\mathrm{T}$, wild type, $n=23$ and mutated, $\mathrm{T} / \mathrm{A}, n=18$, Figure 1). There was no apparent correlation between the expression of SLC5A5 and histopathological features.

\subsection{The Expression of miR-181a-5p Is Upregulated in Tumor Tissue}

The expression of miR-181a-5p in the studied thyroid tissue pairs was increased by $27 \%(p=0.0015, n=49$, Figure 2). No correlation between SLC5A5 and miR-181a-5p expression was found.

\subsection{Genes Expression in TCGA Cohort}

In the TCGA cohort $(n=59)$ we confirmed SLC5A5 downregulation, with a decrease of 13.7-fold ( $p<0.0001$, Figure 3a). This change was accompanied by an increase in miR181a-5p expression (2.27-fold, $p<0.0001$, Figure $3 b$ ). There was weak, negative correlation between the expression of these particles (Spearman's $r-0.39, p=0.002$ ). 
Table 1. Characteristic of PTC patients.

\begin{tabular}{|c|c|c|c|}
\hline \multicolumn{2}{|c|}{ Feature } & \multirow{2}{*}{$\begin{array}{l}\mathbf{N} \\
43\end{array}$} & \multirow{2}{*}{$\begin{array}{c}\mathbf{( \% )} \\
88 \%\end{array}$} \\
\hline & Female & & \\
\hline Sex & Male & 6 & $12 \%$ \\
\hline \multirow{2}{*}{ Histopathological subtype } & PTC cf & 44 & $90 \%$ \\
\hline & PTC fv & 5 & $10 \%$ \\
\hline \multirow{2}{*}{ No. of foci } & Single & 37 & $76 \%$ \\
\hline & Multiple & 12 & $24 \%$ \\
\hline \multirow{2}{*}{ Tumor diameter } & Average & 16.23 & $\mathrm{~mm}$ \\
\hline & Range & $1-73$ & $\mathrm{~mm}$ \\
\hline \multirow{5}{*}{$\mathrm{pT}$ feature } & pT1a & 21 & $43 \%$ \\
\hline & pT1b & 13 & $27 \%$ \\
\hline & pT2 & 6 & $12 \%$ \\
\hline & pT3 & 9 & $18 \%$ \\
\hline & pT4 & 0 & $0 \%$ \\
\hline \multirow{3}{*}{$\mathrm{pN}$ feature } & N0 & 39 & $80 \%$ \\
\hline & N1a & 5 & $10 \%$ \\
\hline & N1b & 5 & $10 \%$ \\
\hline \multirow{2}{*}{ cM feature } & M0 & 48 & $98 \%$ \\
\hline & M1 & 1 & $2 \%$ \\
\hline \multirow{2}{*}{ Vascular invasion } & No & 44 & $90 \%$ \\
\hline & Yes & 5 & $10 \%$ \\
\hline \multirow{3}{*}{ Local invasion } & No & 33 & $67 \%$ \\
\hline & Capsule only & 10 & $20 \%$ \\
\hline & Extrathyroidal & 6 & $12 \%$ \\
\hline \multirow{6}{*}{ Stage } & I & 39 & $80 \%$ \\
\hline & II & 2 & $4 \%$ \\
\hline & III & 5 & $10 \%$ \\
\hline & IVA & 2 & $4 \%$ \\
\hline & IVB & 0 & $0 \%$ \\
\hline & IVC & 1 & $2 \%$ \\
\hline \multirow{2}{*}{ BRAF status ${ }^{1}$} & T (wild type) & 23 & $56 \%$ \\
\hline & T/A (mutated) & 18 & $44 \%$ \\
\hline
\end{tabular}

${ }^{1} \mathrm{BRAF}^{\mathrm{V} 600 \mathrm{~F}}$ mutation was checked in 41 out of 49 patients.

\subsection{Investigation of Binding of miR-181a-5p with $3^{\prime} U T R$ of SLC5A5}

2.4.1. Analysis Employing Broadly Used Algorithms Does Not Reveal Binding of miR-181a-5p with 3'UTR of SLC5A5

None of the used algorithms (i.e., miRanda, TargetRank, mirdb.org, PicTar and DIANA microT-CDS) predicted SLC5A5 3'UTR as a target for miR-181a-5p.

\subsubsection{Identification and Confirmation of miR-181a-5p Binding Site}

We analyzed the $3^{\prime}$ UTR of $S L C 5 A 8$ in the region predicted to interact with miR-181a-5p (Figure 4a, upper part) and found a similar sequence in the $3^{\prime}$ UTR of SLC5A5, between nucleotides 1226 and 1243 (Figure 4a, lower part). We subcloned a 118bp fragment of SLC5A5 3'UTR containing the identified sequence (i.e., nucleotides 1152-1269) into pGL3MCS_down_luc plasmid [26] (pGL3-SLC5A5, as shown in Figure 4b) and mutated two nucleotides (i.e., nucleotides 1241-1242) in the putative binding site (pGL3-SLC5A5_mut, Figure $4 c)$. 


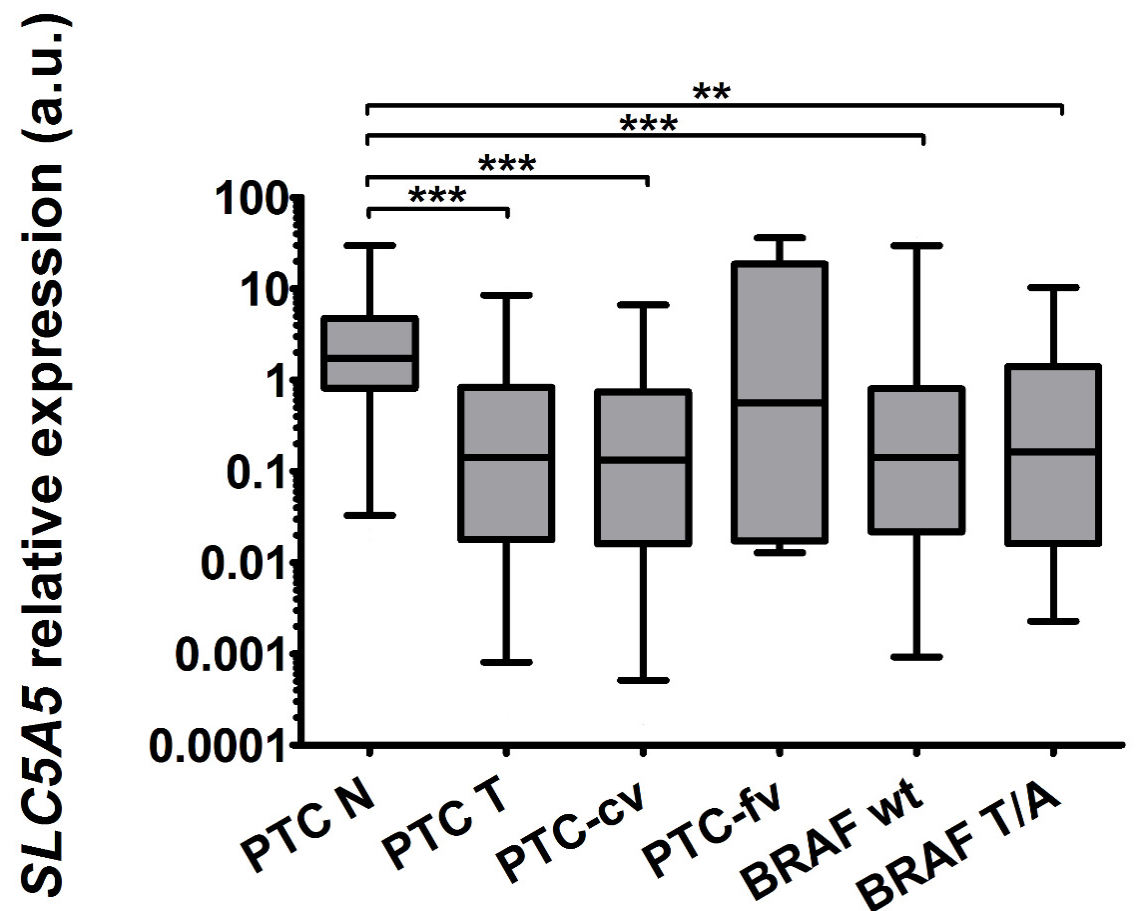

Figure 1. The expression of SLC5A5 was 12.27 -fold $(p<0.0001)$ reduced in PTC (PTC-T, $n=49)$ compared with normal adjacent tissue (PTC-N, $n=49)$. The reduction was more profound in the classic variant of PTC (PTC-cv, $n=44,13.16$-fold, $p<0.0001$ ) compared with the follicular variant (PTC-fv, $n=5,3.11$-fold, non-significant). The reduction was observed both in the BRAF wild-type group (BRAF wt, $n=23,12.27$-fold, $p=0.0009$ ) and BRAF mutated group (BRAF T/A, $n=18$, 10.65-fold, $p=0.007$; please note that expression in tumors was compared with expression in matched controls only). The graph shows the expression of SLC5A5 in thyroid tissue samples normalized against HPRT. Data are expressed as median, interquartile range and 5-95 percentile. Statistical analysis was performed with a Mann-Whitney $U$ test $\left(^{* *} p<0.01\right.$, $\left.^{* * *} p<0.001\right)$. Logarithmic scale was used.

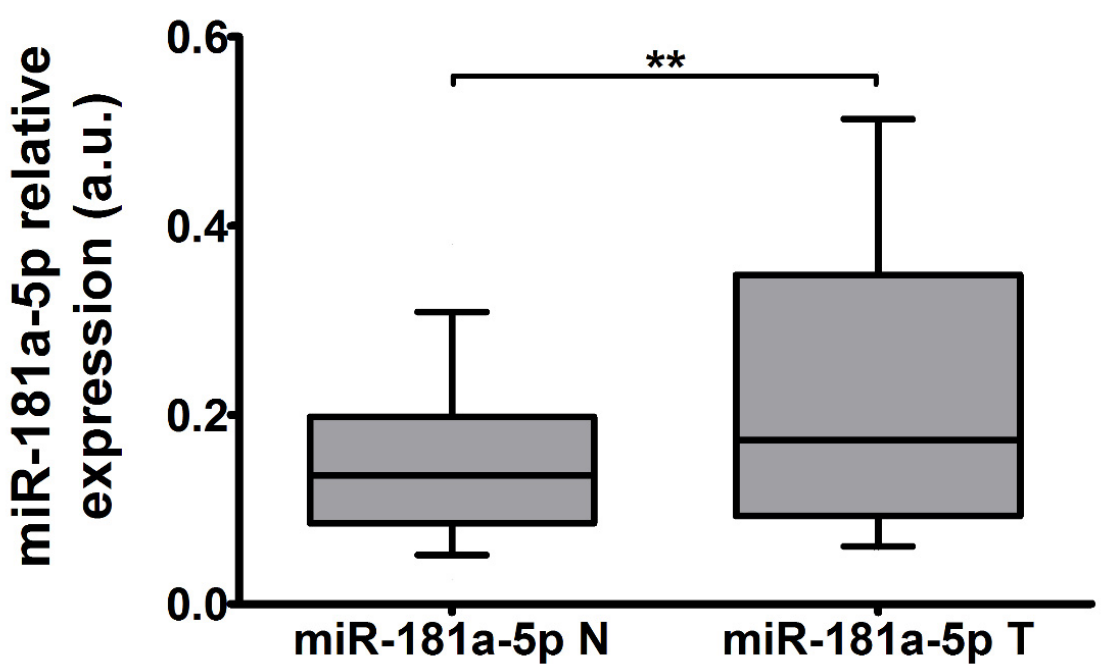

Figure 2. The expression of miR-181a-5p normalized to U44 in PTC-T versus PTC-N tissue $(n=49)$. The expression was increased by $27 \%(p=0.0015)$. Data are expressed as median and $10-90$ percentile. Statistical analysis was performed with a Wilcoxon $t$-test to compare expression of miRNA in PTC-T vs. PTC-N tissue, ${ }^{* *} p<0.01$. 


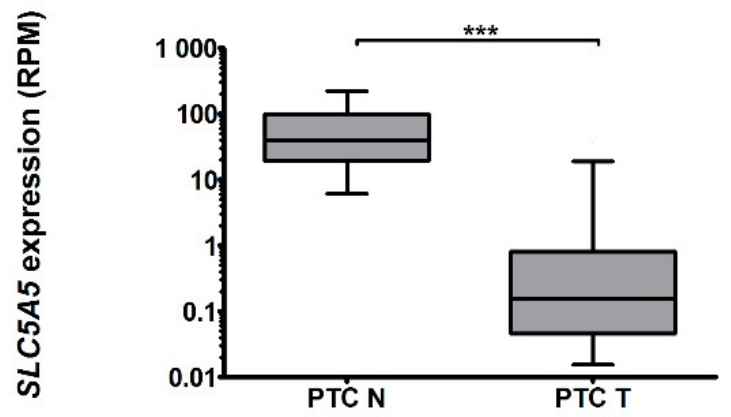

a

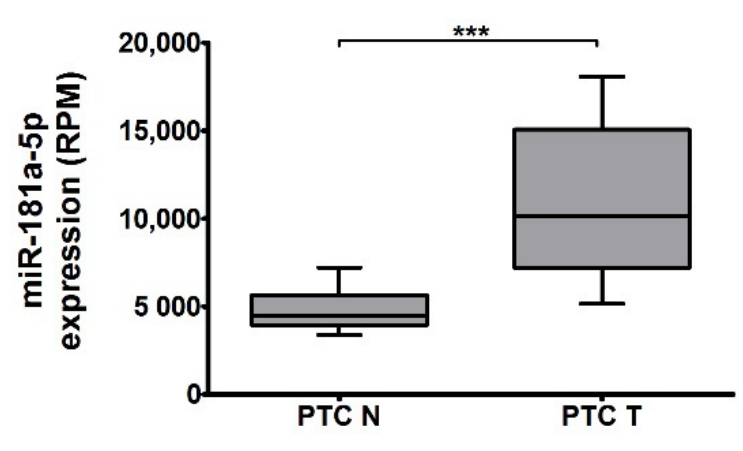

b

Figure 3. In TCGA cohort (a) SLC5A5 expression was decreased in tumor 13.7-fold $(p<0.001)$, whereas (b) miR-181a expression was increased 2.27-fold $(p<0.001)$. Data are expressed as median and 10-90 percentile. Logarithmic scale was used. Statistical analysis was performed with a Wilcoxon $t$-test to compare expression of miRNA in PTC-T vs. PTC-N tissue, $* * * p<0.001$.

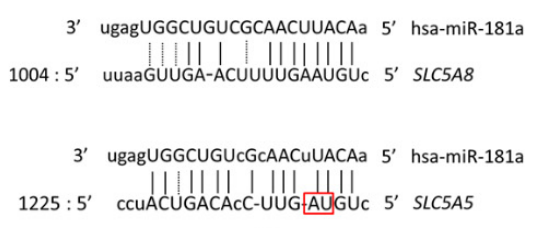

a

PEZX-SLC5A5

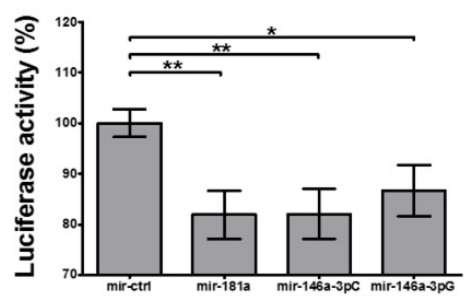

d

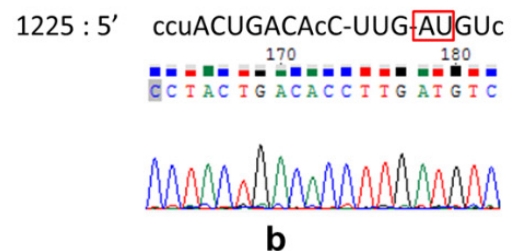

pGL3-SLC5A5

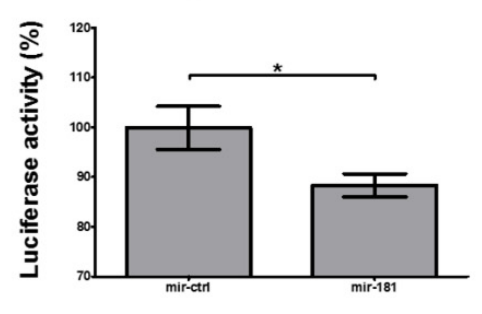

e

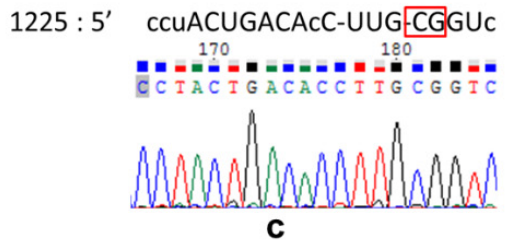

pGL3-SLC5A5_mut

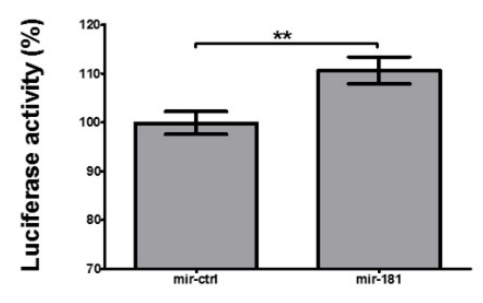

f

Figure 4. (a) In silico analysis revealed similarity between region of $3^{\prime} U T R$ of $S L C 5 A 8$, which binds with miR-181a-5p (upper part), and region of putative binding of miR-181a-5p in 3'UTR of SLC5A5 (lower part; adapted from microrna.org). (b) A 118bp fragment of 3'UTR of SLC5A5, containing a putative binding site for miR-181a-5p, was subcloned into pGL3MCS_down_luc plasmid. (c) Two nucleotides (1241-1242) were mutated in putative binding site. (d) Co-transfection of HeLa cells with pEZX-SLC5A5 and plasmids expressing mir-181a, mir-146a-3pC or mir-146a-3pG resulted in a reduction in luciferase activity by $18(p=0.005), 18(p=0.006)$ and 13\% $(p=0.033)$, respectively, in comparison with mir-ctrl. (e) Cotransfection of HeLa cells with pGL3-SLC5A5, containing a 118bp fragment of 3'UTR of SLC5A5 with putative miR-181a-5p binding site, and plasmids expressing mir-181a, led to a $12 \%(p=0.032)$ decrease in luciferase activity. (f) Co-transfection of HeLa cells with pGL3-SLC5A5_mut, containing a 118bp fragment of 3'UTR of SLC5A5 with mutations in putative miR-181a-5p binding site, and plasmids expressing mir-181a, did not lead to a reduction in luciferase activity-an $11 \%$ $(p=0.0085)$ increase was observed. Luciferase activity is shown as a percentage relative to the control. The results are normalized by Renilla luciferase and derived from three independent experiments, each performed in triplicates. The graph shows the mean, along with deviations from mean (SEM). Statistical analysis was performed using an unpaired $t$-test $\left({ }^{*} p<0.05,{ }^{* *} p<0.01\right)$.

Co-transfection with pEZX-SLC5A5 and mir-181a decreased luciferase activity by $18 \%$ $(p=0.005$, Figure $4 \mathrm{~d})$. A similar effect was observed upon transfection with plasmids expressing two isoforms of mir-146a serving as a positive control, namely mir-146a-3pC or mir-146a-3pG, which led to reduction by $18(p=0.006)$ and $13 \%(p=0.033$, Figure $4 \mathrm{~d})$, respectively. 
When a 118bp fragment of SLC5A5 $3^{\prime} \mathrm{UTR}$, containing the putative binding site of miR181a-5p, was subcloned into a pGL3-SLC5A5 construct, a reduction in luciferase activity was preserved, with a decrease by $12 \%(p=0.032$, Figure $4 \mathrm{e})$. Upon introduction of a mutation in the pGL3-SLC5A5_mut construct, the ability of binding was lost-we observed an unspecific increase in luciferase activity by $11 \%(p=0.0085$, Figure $4 \mathrm{f})$.

\section{5. miR-181a-5p Affects Expression of Endogenous SLC5A5}

\subsubsection{Plasmid Functionality Verification}

Functionality of the mir-expressing plasmid was confirmed in HeLa cells using TaqMan kits. Transfection with mir-181-expressing plasmid led to a 29-fold increase in its expression $(p<0.0001$, Figure $5 a)$. Functionality of sponge-expressing plasmids was verified by co-transfecting HeLa cells with sponge- and microRNA-expressing plasmid with appropriate controls. Co-transfection with an appropriate microRNA-expressing plasmid (i.e., expected to bind to the expressed particle) led to reduction in luciferase activity when compared with control transfections - by $8 \%$ in the case of control plasmids $(p=0.004)$, and by $22 \%$ for sponge- 181 and mir- 181 co-transfection ( $p=0.012$; Figure $5 b$ ).

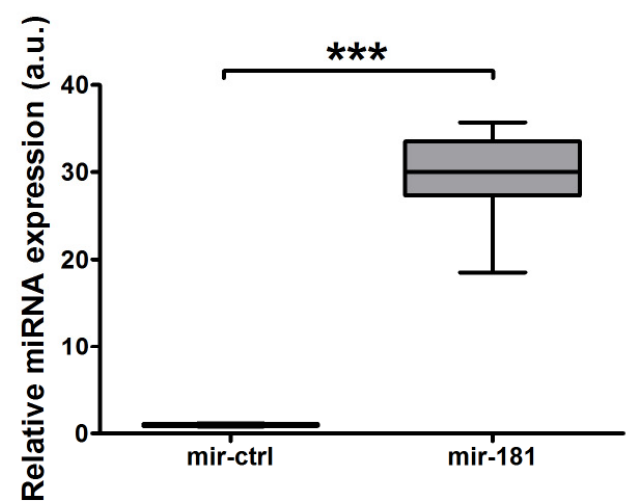

a

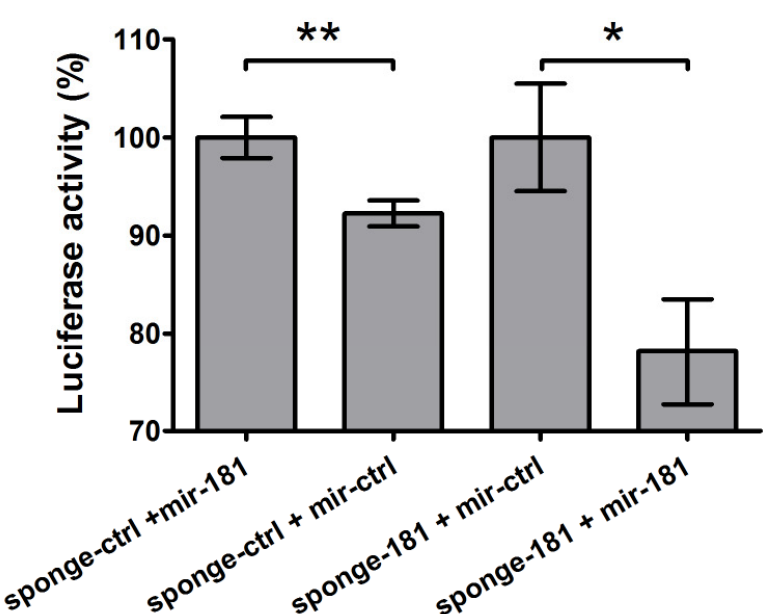

b

Figure 5. Functionality of obtained plasmids. (a) Transfection of HeLa cells with mir-181-expressing plasmid led to an increase in expression of miR-181a-5p measured in real-time PCR by 29-fold ( $p<0.0001)$. (b) Co-transfection of HeLa cells with sponge-ctrl plasmid and mir-ctrl led to a decrease in luminescence activity by $8 \%(p=0.004)$, when compared with co-transfection with sponge-ctrl and mir-181-expressing plasmids. Similarly, co-transfection with sponge-181 and mir-181 decreased luciferase activity by $22 \%(p=0.012)$, when compared with co-transfection with sponge-181 and mir-ctrl. Data are expressed as mean values $+/-$ SEM. Statistical analysis was performed using an unpaired $t$-test $\left({ }^{*} p<0.05,{ }^{* *} p<0.01\right.$, *** $p<0.001)$.

\subsubsection{Impact of Overexpression and Silencing of miR-181a-5p on NIS Expression} and Function

Total RNA isolated from MCF7 cells was submitted to whole transcriptome sequencing, but no significant results were found in the case of both overexpression and silencing of miR-181a-5p.

Transfection of the MCF7 cell line upon induction with ATRA and dexamethasone with plasmids expressing mir-181a resulted in a reduction in SLC5A5 mRNA by $43 \%$ $(p=0.001)$, whereas suppression of miR-181a-5p using an appropriate sponge increased SLC5A5 expression by $45 \%$ ( $p=0.0045$; Figure 6a). When HEK293-flhNIS cells were transfected with plasmids expressing mir-181a, SLC5A5 mRNA was decreased by $24 \%$ $(p=0.0045)$, whereas silencing of miR-181a-5p using an appropriate sponge led to the induction of SLC5A5 expression by $12 \%$ ( $p=0.036$; Figure $6 \mathrm{~b})$. 
MCF7

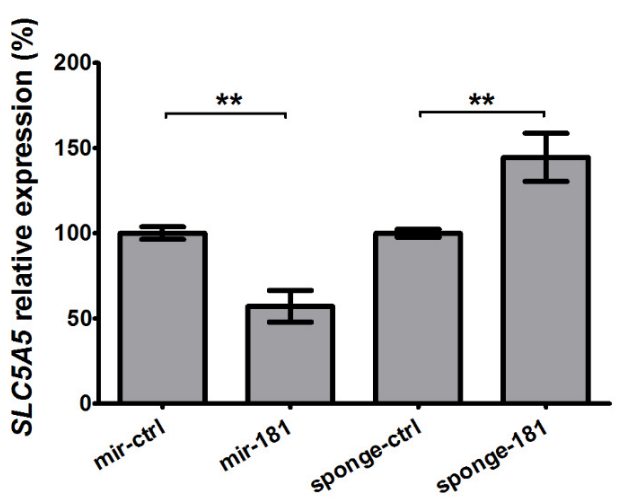

a

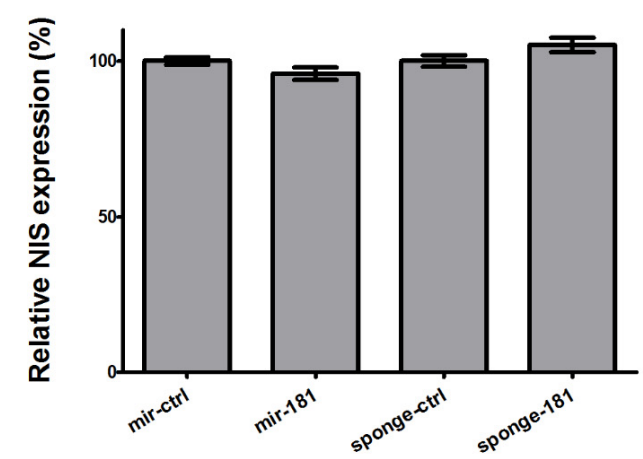

C

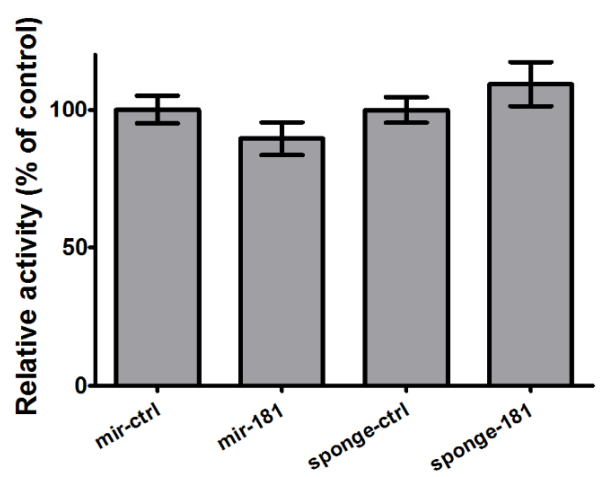

e
HEK293-flhNIS

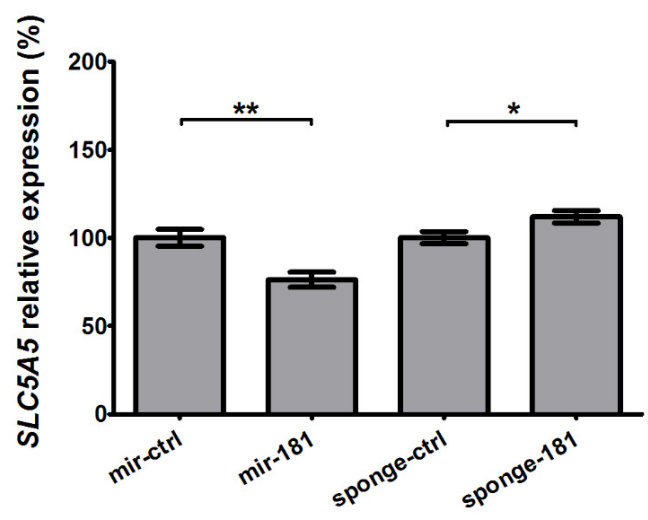

b

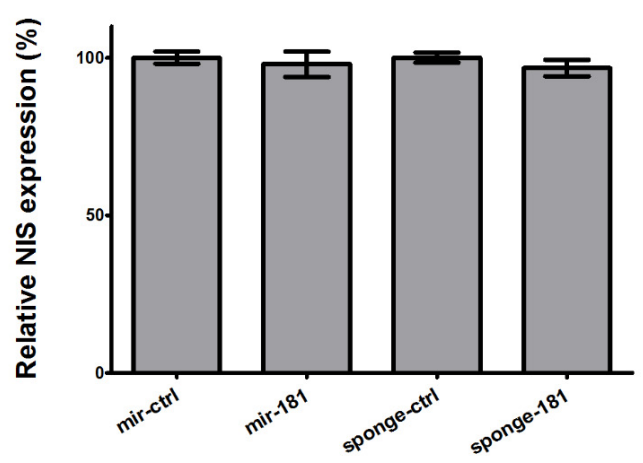

d

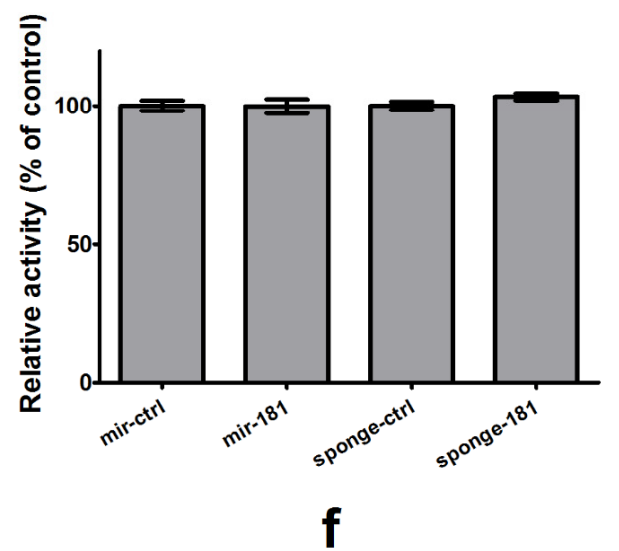

Figure 6. Impact of miR-181a-5p on NIS expression and function. (a) Transfection of MCF7 cells with mir-181-expressing plasmid reduced SLC5A5 mRNA by 43\% ( $p=0.001$ ), whereas silencing of miR-181a-5p using sponge decreased SLC5A5 by $45 \%$ ( $p=0.0045)$. (b) In HEK293-flhNIS, overexpression of mir-181 led to a reduction in SLC5A5 mRNA expression by $24 \%$ $(p=0.0045)$, while miR-181a-5p silencing increased SLC5A5 expression by $12 \%(p=0.036)$. NIS expression measured using ELISA in (c) MCF7 cells induced with all-trans retinoic acid and dexamethasone, and (d) HEK293-flhNIS cells. Tendencies for lower expression upon transfection with mir-181-expressing plasmid are visible for both cell lines. Tendency for higher expression can be seen upon transfection with a plasmid silencing miR-181a-5p in MCF7 cell line. Radioiodine uptake in (e) MCF7 cells induced with all-trans retinoic acid and dexamethasone, and (f) HEK293-flhNIS cells. Tendencies for lower retention upon transfection with mir-181-expressing plasmid and for higher expression upon transfection with a plasmid silencing miR-181a-5p are visible for both cell lines. Data are expressed as mean values $+/-\mathrm{SEM}$. Statistical analysis was performed using a Mann-Whitney test $(\mathbf{a}, \mathbf{b})$ and an unpaired $t$-test $(\mathbf{c}-\mathbf{f}) ;^{*} p<0.05,{ }^{* *} p<0.01$. 
On the protein level, we observed similar, but not statistically significant, tendencies in MCF7 cells (Figure 6c), and a tendency for NIS suppression in HEK293-flhNIS cells upon transfection with mir-181a (Figure 6d). Additionally, in radioactive iodine uptake tests in MCF7 cells the tendencies were clear (Figure 6e), whereas in HEK293-flhNIS cells they were barely visible (Figure 6f).

A graphical summary of the study is shown in Figure 7.

\section{Normal thyroid}

Colloid

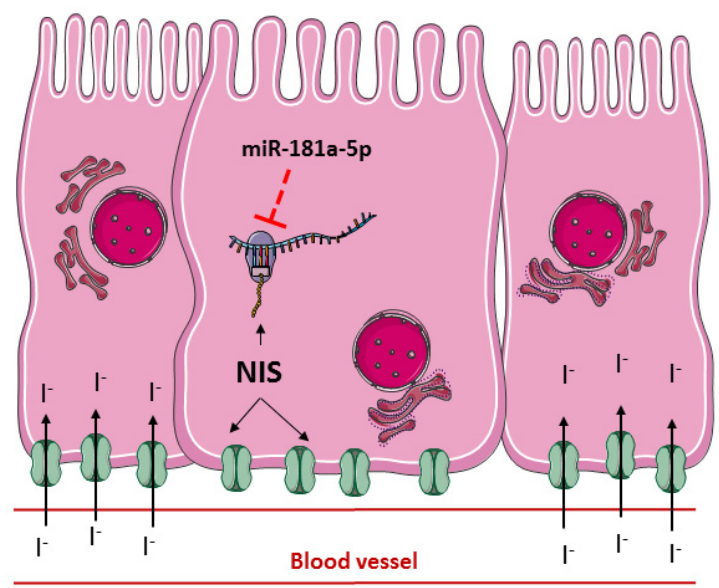

a

\section{Papillary carcinoma (PTC)}

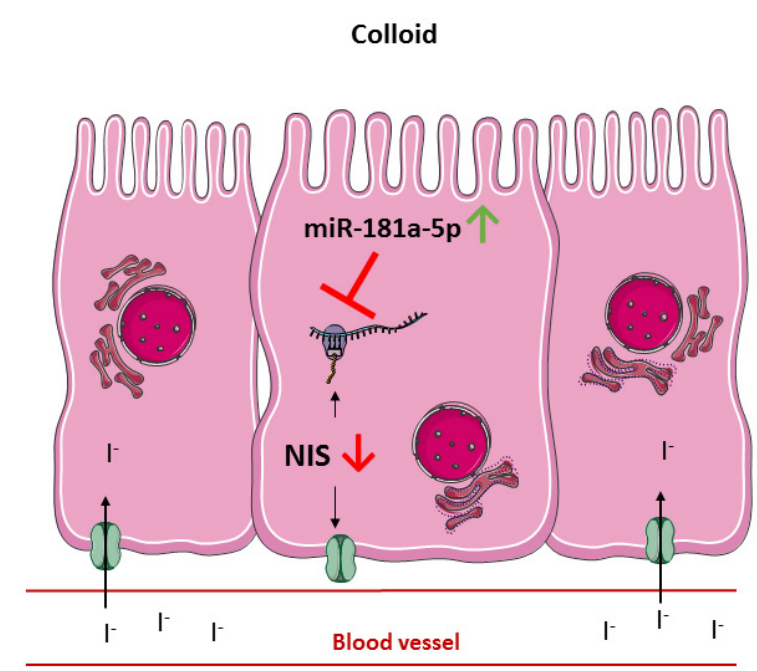

b

Figure 7. Graphical summary of the study. MicroRNA miR-181a-5p regulates NIS, (a) leading to fine-tuning of NIS in normal thyroid tissue, and (b) contributing to severe NIS downregulation in the context of PTC. Figure contains elements available at Servier Medical Art repository, licensed under a Creative Commons Attribution 3.0 Unported License. http:/ / smart.servier.com/ accessed 28 March 2021.

\section{Discussion}

In this study, we show, for the first time, that miR-181a-5p directly regulates expression of SLC5A5. Our study adds a new part of the puzzle, after reports regarding miR-146a-3p, miR-146b-3p, miR-339-5p and miR-875-5p.

NIS, a protein encoded by the SLC5A5 gene, is crucial for thyroid physiology, and in the case of differentiated thyroid carcinomas, such as PTC, is essential to enable radioiodine therapy, which is an important part of adjuvant PTC treatment [27]. Numerous previous studies, including TCGA, provide data regarding the reduction in SLC5A5 expression in PTC (some of the studies were revised recently [28]). Our results confirm these findings. On the contrary to previous reports, in our cohort SLC5A5 expression in tumor did not depend on $\mathrm{BRAF}^{\mathrm{V} 600 \mathrm{E}}$ status, but this may result from population differences. It should be also emphasized that NIS function may be impaired by BRAF ${ }^{\mathrm{V} 600 \mathrm{E}}$ mutation not only through downregulation, but also by impaired trafficking to the cell membrane [29]. $\mathrm{BRAF}^{\mathrm{V} 600 \mathrm{E}}$ mutation was proposed as a predictor of radioiodine therapy effectiveness in PTC [30]; however, data undermining this approach also exist [31,32]. What is more, clinical studies which tested the ability of MAPK pathway inhibitors, including BRAF inhibitors, resulted in rather disenchanting effects (as revised in [33]). Thus, it seems that the presence of a $\mathrm{BRAF}^{\mathrm{V} 600 \mathrm{E}}$ mutation is not a sufficient condition for resistance to radioiodine therapy.

The role of microRNA-mediated gene regulation is a growing matter of interest in thyroid carcinomas. As mentioned, so far regulation of NIS by miR-146a-3p, miR-146b$3 p$, miR-339-5p and miR-875-5p was shown. Our previous, unpublished data draw our attention to miR-181a-5p as another putative suppressor of NIS. Data regarding miR-181a$5 p$ in PTC is not vast; however, recent analysis underlined its putatively important role as 
a factor contributing to dysregulation of numerous genes [34]. In our cohort, miR-181a-5p was overexpressed in PTC, which stands in line with previous findings [17,35]. We did not observe higher levels of miR-181a-5p in the case of $\mathrm{BRAF}^{\mathrm{V} 600 \mathrm{E}}$ mutation, similarly to a recent Czech study [36], but on the contrary to a previous study in the Chinese population [37]. We also did not find a negative correlation between SLC5A5 and miR-181a$5 p$, but we noted such a correlation in the TCGA cohort. Lack of a negative correlation in our cohort may mirror the complexity of regulation of SLC5A5 expression in PTC. It is worth emphasizing that dividing PTC cases into BRAF-like and RAS-like does not exhaust the complexity of its genetics $[9,38]$.

As the broadly used algorithms $[39,40]$ did not predict interaction between miR-181a$5 p$ and SLC5A5 $3^{\prime}$ UTR, we further investigated SLC5A5 $3^{\prime}$ UTR, among others, scanning for similarity with $S L C 5 A 83^{\prime}$ UTR, which we have shown to interact with miR-181a-5p previously [25]. Indeed, we found a similar sequence down $1225 \mathrm{nt}$ of the $3^{\prime} \mathrm{UTR}$ of SLC5A5. Using a luciferase assay, we confirmed that the product from the mir-181 precursor interacts with the SLC5A5 3'UTR, as was previously shown for mir-146a (for its two alleles, differing by a single nucleotide polymorphism $[20,26])$. Interaction was maintained when a $118 \mathrm{nt}$ fragment, containing an identified region, was subcloned into another plasmid, but was abolished upon introducing mutations at the predicted binding site. The binding site is not a canonical one, with at least six consecutive, complementary nucleotides [41], nor a non-canonical type, with a bulge within $3^{\prime}$ UTR [42] - in our case the expected bulge occurs in a microRNA strand. Perfect pairing may be observed, among others, in the case of nucleotides $2-4$ of miR-181a-5p, which is essential for the initial step of microRNA interaction with targeted mRNA [43], whereas the complementarity of nucleotides 4-5 allows for strong binding [44]. A bulge nucleotide within microRNA does not exclude the interaction; what is more, pairing at the $3^{\prime}$ end of microRNAs (especially involving nucleotides 13-16, as in this case) can compensate for seed mismatches [15]. Experimental identification of the microRNA binding site (accordingly to [45]), which was not predicted by broadly used algorithms, is one of the main strengths of the study.

We showed that overexpression of miR-181a-5p (using a mir-expressing plasmid) led to downregulation of SLC5A5 mRNA in both MCF7 and HEK293-flhNIS cell lines, whereas silencing of miR-181a-5p resulted in its upregulation. We checked for whole-transcriptome effects using NGS, but the results speak against serious deregulation of numerous genes at the whole transcriptome level. Tendencies similar to changes observed at the RNA level were shown at the level of protein expression and cell function, measured as radioiodine uptake. Dysregulation at the protein level was not more prominent than at the RNA level, which is in agreement with the findings that in mammals mRNA destabilization is the main effect of microRNA action [46], thus mRNA changes are believed to provide a nearly quantitative readout of the miRNA-mediated repression [47]. It should be emphasized that a decrease in radioiodine accumulation may be partially compromised by a simultaneous decrease in radioiodine efflux, as miR-181a-5p regulates SLC5A8 [25], encoding the apical iodine transporter, and is predicted (by miRanda, TargetRank, and DIANA microT-CDS) to target SLC26A4, encoding pendrin, both of which probably take part in mediating the efflux [48]. This stands in line with the concept that a single microRNA may regulate different genes involved in a single process through canonical and non-canonical interactions [49]. The use of MCF7 and HEK293-flhNIS cell lines instead of the thyroid cancer-derived cell line may be seen as a limitation; however, human thyroid cancer cell lines exhibit barely detectable levels of NIS, similarly to the tumor tissue, making such a study hard to perform. Importantly, both cell lines used in the study are accepted models and were previously used for a similar purpose $[20,23]$. Since the principle of action of microRNAs on the target gene does not depend on cell type, the finding that miR-181a-5p directly reduces SLC5A5 expression in MCF7 and HEK293-flhNIS cells could be extended to suggest that overexpression of miR-181a-5p at least in part accounts for the reduced expression of SLC5A5 in PTC. 
To conclude, reduced expression of NIS in PTC seems to result, among other factors, from upregulation of miR-181a-5p. This phenomenon may contribute to resistance to radioactive iodine therapy, and the significance of miR-181a-5p as predictor of treatment efficiency remains to be elucidated. Since microRNA levels can be modulated, miR-181a-5p should be considered a promising therapeutic target.

\section{Materials and Methods}

\subsection{Tissue Samples}

Tissue samples were obtained with the permission of the Bioethics Committee of the Medical University of Warsaw (no. KB/184/2009) from patients with papillary thyroid carcinoma and collected at Genomic Medicine, Medical University of Warsaw. Each patient signed informed consent prior to surgery. The samples consisted of two groups: cancer tissue ( $n=49$, PTC-T) and control tissue (paired normal tissue from the same patient; $n=49$, PTC-N). PTC was diagnosed by histology according to World Health Organization 2004 criteria. The patients represented all stages of the disease excluding IVB; $44(90 \%)$ tumors represented the classic variant of PTC (PTCcv) and $5(10 \%)$ were the follicular variant of PTC (PTCfv). The medium tumor diameter was $16.23 \mathrm{~mm}$ (range: 1-73 mm). Patient characteristics are summarized in Table $1 . \mathrm{BRAF}^{\mathrm{V} 600 \mathrm{E}}$ mutation status was checked as described previously [17] in 41/49 tumors, identifying the mutation in 18 of them.

\subsection{Real-Time PCR}

Total RNA was extracted with a standard TRIzol-chlorophorm method (RNA Extracol, EURx, Gdańsk, Poland). Quality and concentration of RNA was assessed using a NanoDrop2000 spectrophotometer (Thermo Scientific, Waltham, MA, USA); A260/280 and A260/230 ratios between 1.8 and 2.2 were considered as satisfactory. To establish SLC5A5 mRNA level, RNA was reverse transcribed using M-MLV reverse transcriptase (Promega, Madison, WI, USA), and gene expression was analyzed in a real-time SQ-PCR assay using a Light Cycler 480 (Roche, Basel, Switzerland). HPRT served as an internal control. Primers are listed in Table S1. Reverse transcription and real-time PCR of miR-181a-5p was performed using a specific TaqMan probe with U44 as an internal control (Life Technologies, Waltham, MA, USA, cat. no. 000480 and 001094, respectively). Relative quantification of expressed RNA was calculated using the standard $2^{-\Delta \mathrm{Ct}}$ method.

\subsection{Comparison of the Results with the TCGA Data}

The Cancer Genome Atlas data was accessed 11 February 2016 using the tcga-data.nci. nih.gov portal. We identified 59 cases for whom the mRNA-Seq and miRNA-Seq level 3 data for tumor and healthy control tissue were available. Expression of SLC5A5, miR-181a1-5p and miR-181a-2-5p were normalized as reads per million (RPM). The obtained normalized data was used for the analysis of expression and correlation between the SLC5A5 and miRNA. Subgroups of PTCcv vs. PTCfv and BRAF wild-type vs. V600E-mutated were analyzed. Since the miR-181a-1 and miR-181a-2 isoforms are undistinguishable in the TaqMan analysis, both isoforms were counted together, according to the conception of "seed power", i.e., the conception that all the miRNAs regulate common target genes [50].

\subsection{In Silico Identification of Binding Site of miR-181a-5p in SLC5A5 3'UTR}

Sequence of SLC5A5 3'UTR (1297nt) was obtained from Ensembl Database (www. ensembl.org, accessed on 2 May 2014). MicroRNAs potentially binding SLC5A5 3'UTR were predicted using miRanda algorithm (microrna.org), TargetRank (http:/ / genes.mit. edu/targetrank/), mirdb.org, PicTar (https:/ / pictar.mdc-berlin.de/) and DIANA microTCDS (http:/ / diana.imis.athena-innovation.gr/DianaTools/index.php?r=MicroT_CDS, all accessed on 19 October 2018). Clone Manager [51] was used for analyzing SLC5A5 3'UTR, including comparison with different targets of miR-181a-5p, planning cloning of its fragment and planning mutagenesis. 


\subsection{MicroRNA Cloning and MicroRNA-Sponges Preparation}

The influence of miRNA-181a-5p on endogenous SLC5A5 levels was analyzed using microRNA- and microRNA-sponge-expressing plasmids. The sequence encoding the precursor (referred to as mir) for miR-181a-5p was identified based on the Ensembl Database (www.ensembl.org, accessed on 2 May 2014). Primer pairs (Table S1) were created using Clone Manager [51], and restriction sites for HindIII (forward primer) and EcoRV (reverse primer) were added. Formation of hairpin structure by the product was confirmed with RNA Shapes software (https:/ / bibiserv2.cebitec.uni-bielefeld.de/rnashapes, accessed on 2 May 2014). Precursors were amplified on the template of DNA isolated from leukocytes of healthy donors using Opti Taq 2x PCR Master Mix (EURx). The product and the pcDNA3 plasmid (Life Technologies) were digested with the HindIII and EcoRV restriction enzymes (Promega) and ligated using T4 ligase (Promega). As the cloned sequence contained microRNA precursor, the plasmid is referred to as "mir-expressing" [52]. A control sequence (Table S1), expected to be transcribed and processed like microRNAs, but not targeting any $3^{\prime}$ UTRs, was cloned similarly.

A tandem sequence complementary to the binding site of miR-181a-5p was synthetized, amplified using primers containing restriction sites for XhoI and PstI (Table S1) and cloned into pGL3-MCS_down_luc, pGL3 plasmid with multicloning site moved downstream of luciferase gene [26], resulting in microRNA sponges [53]. Its specificity was confirmed using MirTarget algorithm (www.mirdb.org, accessed on 10 February 2019). A control sequence, expected to bind with barely any microRNAs, was synthetized and cloned similarly (Table S1).

All constructs were sequenced using Sanger technique. Overexpression upon transfection with expressing plasmid was confirmed in HeLa cells using a TaqMan kit. MicroRNA sponge was validated in HeLa cells co-transfected with the sponge and mir-181a-expressing plasmid. HeLa cells (obtained from ATCC ${ }^{\circledR}$, passage 9th to 12th) were seeded on 12-well plates, $2 \times 10^{5}$ cells per well, and after $24 \mathrm{~h}$ transfected in combinations with $500 \mathrm{ng}$ of mir-181 or mir-ctrl and $100 \mathrm{ng}$ of sponge-181a or sponge-ctrl. As a control, $500 \mathrm{ng}$ of pRL-TK plasmid (Promega), expressing Renilla luciferase was used. Then, $48 \mathrm{~h}$ after transfection, cells were subjected to luciferase assay (Promega), using GloMax-Multi Detection System (Promega) according to the manufacturer's protocol.

\subsection{Analysis of miR-181a-5p-Mediated Regulation of SLC5A5}

Direct binding of miR-181a-5p to SLC5A5 was analyzed using luciferase assay. HeLa cells (obtained from ATCC ${ }^{\circledR}$, passage 9th to 12th) were transfected with the pEZX-SLC5A5 reporter vector (GeneCopoeia, Rockville, MD, USA, cat. no. HmiT017390-MT01) containing the $3^{\prime}$ UTR of SLC5A5 cloned downstream of the coding sequence of the firefly luciferase, and with mir-expressing plasmids. Plasmids expressing miR-146a-3pC and miR-146a-3pG served as a positive control [20]. Then, $48 \mathrm{~h}$ after pEZX-SLC5A5 transfection, cells were subjected to luciferase assay (Promega), using GloMax-Multi Detection System (Promega) according to the manufacturer's protocol. Constitutively expressed Renilla luciferase served as the internal control. Subsequently, binding region in SLC5A5 3'UTR was identified by subcloning and mutagenesis, as described in the Results.

To analyze the effect of miR-181a on endogenous SLC5A5 expression, appropriate mir- or sponge-expressing plasmids were used. MCF-7 cells (ATCC ${ }^{\circledR}$ HTB-22 ${ }^{\mathrm{TM}}$ ) were seeded in medium containing 45\% DMEM, 45\% F-12 and 10\% FBS with addition of $1 \mu \mathrm{M}$ of all-trans-retinoic acid and dexamethasone (compounds inducing NIS expression [54,55]) onto 12-well plates using $2 \times 10^{5}$ cells per well. HEK293-flhNIS, stably transfected with fulllength (i.e., including $5^{\prime}$ and $3^{\prime}$ UTR sequences [56]) cells were seeded in DMEM medium onto 12 -well plates using $2 \times 10^{5}$ cells per well. After $24 \mathrm{~h}$, cells were transfected with $500 \mathrm{ng}$ of miRNA-expressing plasmid or $100 \mathrm{ng}$ of sponge-expressing plasmid. Cells were incubated for $48 \mathrm{~h}$, and subsequently RNA was extracted for gene expression quantification.

Total RNA isolated from MCF-7 cells was subjected to transcriptome sequencing (RNA-Seq; performed by Warsaw Genomics, Warsaw, Poland). 


\subsection{Protein Quantification}

In parallel to transfections described above, cells were seeded onto 6-well plates and transfected using microRNA- or sponge-expressing plasmids using 2-fold higher amounts of all the reagents. Subsequently, cells were detached using Accutase (Sigma-Aldrich, Saint Louis, MO, USA) and protein was isolated using RIPA Lysis and Extraction Buffer (Thermo Fisher Scientific, Waltham, MA, USA) with $0.5 \mathrm{mM}$ PMSF and cOmplete ${ }^{\mathrm{TM}}$ protease inhibitor cocktail (Roche Diagnostics). Protein concentration was measured using Pierce BCA Protein Assay Kit (Thermo Fisher Scientific). Then, $2 \mu \mathrm{g}$ of total protein was subjected to NIS quantification using Human NIS ELISA kit (ELK Biotechnology, Wuhan, China, cat. no. ELK4300), according to manufacturer's instruction.

\subsection{Radioactive Iodine Uptake Assay}

The effect of miR-181a-5p on the metabolism of radioactive iodine (RAI) was analyzed in MCF-7 and HEK293-flhNIS, treated as described above. Then, $48 \mathrm{~h}$ after transfection, $10 \mu \mathrm{Ci}$ of $\mathrm{Na}^{131} \mathrm{I}$ (Polatom, Otwock, Poland) in a final concentration of $25 \mathrm{uM}$ was added to each well. Plates were incubated for $30 \mathrm{~min}$, washed with PBS twice and fresh medium was added. Retained activity was checked at Cyclone Plus (PerkinElmer, Shelton, CT, USA) by 10-min irradiation of phosphor imager screen. Results were normalized as percentage of activity of control-transfected cells.

\subsection{Statistical Analysis}

Each experimental series was compared with an appropriate control set. Normally distributed data were analyzed using the Student's $t$-test, non-normally distributed data were analyzed using Wilcoxon and Mann-Whitney U tests and correlation analysis was performed using Spearman's rank correlation coefficient (r). Statistical analysis was performed using GraphPad Prism [57]. p-values $<0.05$ were considered significant.

Supplementary Materials: The following are available online at https:/ /www.mdpi.com/article/10 $.3390 /$ ijms22116067/s1.

Author Contributions: Conceptualization, W.G.; methodology, W.G., Ł.C., Z.R. and M.K.-Ł.; validation, W.G., K.B., Ł.C., Z.R. and M.K.-Ł., formal analysis, W.G.; investigation, W.G., K.B., Ł.C., Z.R. and M.K.-Ł.; resources, W.G., Ł.C., Z.R. and M.K.-Ł.; data curation, W.G.; writing-original draft preparation, W.G.; writing-review and editing, W.G., K.B., Ł.C., Z.R. and M.K.-Ł.; visualization, W.G.; supervision, W.G.; project administration, W.G.; funding acquisition, W.G. All authors have read and agreed to the published version of the manuscript.

Funding: This study was funded by a European Thyroid Association Research Grant (to W.G.). W.G. was supported by a Polish National Science Center Preludium Grant (2015/17/N/NZ2/01856).

Institutional Review Board Statement: The study was conducted according to the guidelines of the Declaration of Helsinki, and approved by the Bioethics Committee of the Medical University of Warsaw (no. KB/184/2009).

Informed Consent Statement: Informed consent was obtained from all subjects involved in the study.

Data Availability Statement: The data presented in this study are available on request from the corresponding author.

Conflicts of Interest: The authors declare no conflict of interest. The funders had no role in the design of the study; in the collection, analyses, or interpretation of data; in the writing of the manuscript or in the decision to publish the results.

\section{References}

1. Baumann, E. Über Das Thyrojodin; Springer: Berlin/Heidelberg, Germany, 1896.

2. Hertz, S.; Roberts, A.; Means, J.H.; Evans, R.D. Radioactive Iodine as an Indicator in Thyroid Physiology: Iodine Collection by Normal and Hyperplastic Thyroids in Rabbits. Am. J. Physiol. Leg. Content 1940, 128, 565-576. [CrossRef]

3. Seidlin, S.M.; Marinelli, L.D.; Oshry, E. Radioactive Iodine Therapy; Effect on Functioning Metastases of Adenocarcinoma of the Thyroid. J. Am. Med. Assoc. 1946, 132, 838-847. [CrossRef] 
4. Ravera, S.; Reyna-Neyra, A.; Ferrandino, G.; Amzel, L.G.; Carrasco, N. The Sodium/Iodide Symporter (Nis): Molecular Physiology and Preclinical and Clinical Applications. Annu. Rev. Physiol. 2017, 79, 261-289. [CrossRef]

5. Wolff, J. Transport of Iodide and Other Anions in the Thyroid Gland. Physiol. Rev. 1964, 44, 45-90. [CrossRef]

6. Smanik, P.A.; Liu, Q.; Furminger, T.L.; Ryu, K.; Xing, S.; Mazzaferri, E.L.; Jhiang, S.M. Cloning of the Human Sodium Lodide Symporter. Biochem. Biophys. Res. Commun. 1996, 226, 339-345. [CrossRef]

7. Smanik, P.A.; Ryu, K.Y.; Theil, K.S.; Mazzaferri, E.L.; Jhiang, S.M. Expression, Exon-Intron Organization, and Chromosome Mapping of the Human Sodium Iodide Symporter. Endocrinology 1997, 138, 3555-3558. [CrossRef] [PubMed]

8. Mao, Y.; Xing, M. Recent Incidences and Differential Trends of Thyroid Cancer in the USA. Endocr. Relat. Cancer 2016, 23, 313-322. [CrossRef] [PubMed]

9. The Cancer Genome Atlas Research Network. Integrated Genomic Characterization of Papillary Thyroid Carcinoma. Cell 2014, 3, 676-690.

10. Mathur, A.; Moses, W.; Rahbari, R.; Khanafshar, E.; Duh, Q.Y.; Clark, O.; Kebebew, E. Higher Rate of Braf Mutation in Papillary Thyroid Cancer over Time: A Single-Institution Study. Cancer 2011, 117, 4390-4395. [CrossRef] [PubMed]

11. Riesco-Eizaguirre, G.; Rodríguez, I.; De la Vieja, A.; Costamagna, E.; Carrasco, N.; Nistal, M.; Santisteban, P. The Brafv600e Oncogene Induces Transforming Growth Factor Beta Secretion Leading to Sodium Iodide Symporter Repression and Increased Malignancy in Thyroid Cancer. Cancer Res. 2009, 69, 8317-8325. [CrossRef] [PubMed]

12. Costamagna, E.; García, B.; Santisteban, P. The Functional Interaction between the Paired Domain Transcription Factor Pax8 and Smad3 Is Involved in Transforming Growth Factor-Beta Repression of the Sodium/Iodide Symporter Gene. J. Biol. Chem. 2004, 279, 3439-3446. [CrossRef] [PubMed]

13. Zhang, Z.; Liu, D.; Murugan, A.K.; Liu, Z.; Xing, M. Histone Deacetylation of Nis Promoter Underlies Braf V600e-Promoted Nis Silencing in Thyroid Cancer. Endocr. Relat. Cancer 2014, 21, 161-173. [CrossRef] [PubMed]

14. Riesco-Eizaguirre, G.; Gutiérrez-Martínez, P.; García-Cabezas, M.A.; Nistal, M.; Santisteban, P. The Oncogene Braf V600e Is Associated with a High Risk of Recurrence and Less Differentiated Papillary Thyroid Carcinoma Due to the Impairment of Na+/ITargeting to the Membrane. Endocr. Relat. Cancer 2006, 13, 257-269. [CrossRef] [PubMed]

15. Friedman, R.C.; Farh, K.K.; Burge, C.B.; Bartel, D.P. Most Mammalian Mrnas Are Conserved Targets of Micrornas. Genome Res. 2009, 19, 92-105. [CrossRef]

16. Bartel, D.P. Micrornas: Target Recognition and Regulatory Functions. Cell 2009, 2, 215-233. [CrossRef]

17. Swierniak, M.; Wojcicka, A.; Czetwertynska, M.; Stachlewska, E.; Maciag, M.; Wiechno, W.; Gornicka, B.; Bogdanska, M.; Koperski, L.; de la Chapelle, A.; et al. In-Depth Characterization of the Microrna Transcriptome in Normal Thyroid and Papillary Thyroid Carcinoma. J. Clin. Endocrinol. Metab. 2013, 8, E1401-E1409. [CrossRef]

18. Wojcicka, A.; Kolanowska, M.; Jazdzewski, K. Mechanisms in Endocrinology: Microrna in Diagnostics and Therapy of Thyroid Cancer. Eur. J. Endocrinol. 2016, 174, R89-R98. [CrossRef]

19. Lindow, M.; Kauppinen, S. Discovering the First Microrna-Targeted Drug. J. Cell Biol. 2012, 199, 407-412. [CrossRef]

20. Kotlarek, M.; Kubiak, A.; Czetwertynska, M.; Swierniak, M.; Gierlikowski, W.; Kolanowska, M.; Bakula-Zalewska, E.; Jhiang, S.M.; Jazdzewski, K.; Wojcicka, A. The Rs2910164 Genetic Variant of Mir-146a-3p Is Associated with Increased Overall Mortality in Patients with Follicular Variant Papillary Thyroid Carcinoma. Int. J. Mol. Sci. 2018, 19, 655. [CrossRef] [PubMed]

21. Riesco-Eizaguirre, G.; Wert-Lamas, L.; Perales-Patón, J.; Sastre-Perona, A.; Fernández, P.L.; Santisteban, P. The Mir-146b$3 \mathrm{p} /$ Pax8/Nis Regulatory Circuit Modulates the Differentiation Phenotype and Function of Thyroid Cells During Carcinogenesis. Cancer Res. 2015, 75, 4119-4130. [CrossRef]

22. Li, L.; Lv, B.; Chen, B.; Guan, M.; Sun, Y.; Li, H.; Zhang, B.; Ding, C.; He, S.; Zeng, Q. Inhibition of Mir-146b Expression Increases Radioiodine-Sensitivity in Poorly Differential Thyroid Carcinoma Via Positively Regulating Nis Expression. Biochem. Biophys. Res. Commun. 2015, 462, 314-321. [CrossRef] [PubMed]

23. Lakshmanan, A.; Wojcicka, A.; Kotlarek, M.; Zhang, X.; Jazdzewski, K.; Jhiang, S.M. Microrna-339-5p Modulates Na+/ISymporter-Mediated Radioiodide Uptake. Endocr. Relat. Cancer 2015, 1, 11-21. [CrossRef]

24. Tang, Y.; Meng, X.; Yu, X.; Shang, H.; Chen, S.; Liao, L.; Dong, J. Inhibition of Microrna-875-5p Promotes Radioiodine Uptake in Poorly Differentiated Thyroid Carcinoma Cells by Upregulating Sodium-Iodide Symporter. J. Endocrinol. Invest. 2020, 43, 439-450. [CrossRef] [PubMed]

25. Wojcicka, A.; Gierlikowski, W.; Kotlarek, M.; Koperski, L.; Jazdzewski, K. Apical Iodide Transporter (Ait) and Its Microrna -Induced Silencing in Thyroid Malignancies. Endocr. Rev. 2014, 25, P1125.

26. Jazdzewski, K.; Murray, E.L.; Franssila, K.; Jarzab, B.; Schoenberg, D.R.; de la Chapelle, A. Common Snp in Pre-Mir-146a Decreases Mature Mir Expression and Predisposes to Papillary Thyroid Carcinoma. Proc. Natl. Acad. Sci. USA 2008, 105, 7269-7274. [CrossRef]

27. Haugen, B.R.; Alexander, E.K.; Bible, K.C.; Doherty, G.M.; Mandel, S.J.; Nikiforov, Y.E.; Pacini, F.; Randolph, G.W.; Sawka, A.M.; Schlumberger, M.; et al. 2015 American Thyroid Association Management Guidelines for Adult Patients with Thyroid Nodules and Differentiated Thyroid Cancer: The American Thyroid Association Guidelines Task Force on Thyroid Nodules and Differentiated Thyroid Cancer. Thyroid 2016, 26, 1-133. [CrossRef]

28. de Morais, R.M.; Sobrinho, A.B.; Silva, C.M.d.; de Oliveira, J.R.; da Silva, I.C.R.; Nóbrega, O.d. The Role of the Nis (Slc5a5) Gene in Papillary Thyroid Cancer: A Systematic Review. Int. J. Endocrinol. 2018, 2018, 1-11. [CrossRef] 
29. Tavares, C.; Coelho, M.J.; Eloy, C.; Melo, M.; da Rocha, A.G.; Pestana, A.; Batista, R.; Ferreira, L.B.; Rios, E.; Selmi-Ruby, S.; et al. Nis Expression in Thyroid Tumors, Relation with Prognosis Clinicopathological and Molecular Features. Endocr. Connect 2018, 7, 78-90. [CrossRef]

30. Ge, J.; Wang, J.; Wang, H.; Jiang, X.; Liao, Q.; Gong, Q.; Mo, Y.; Li, G.; Li, H.; Xiong, W.; et al. The Braf V600e Mutation Is a Predictor of the Effect of Radioiodine Therapy in Papillary Thyroid Cancer. J. Cancer 2020, 11, 932-939. [CrossRef]

31. Daliri, M.; Abbaszadegan, M.R.; Bahar, M.M.; Arabi, A.; Yadollahi, M.; Ghafari, A.; Taghehchian, N.; Zakavi, S.R. The Role of Braf V600e Mutation as a Potential Marker for Prognostic Stratification of Papillary Thyroid Carcinoma: A Long-Term Follow-up Study. Endocr. Res. 2014, 39, 189-193. [CrossRef]

32. Li, J.; Liang, J.; Zhao, T.; Lin, Y. Noninferior Response in Braf(V600e) Mutant Nonmetastatic Papillary Thyroid Carcinoma to Radioiodine Therapy. Eur. J. Nucl. Med. Mol. Imaging 2016, 43, 1034-1039. [CrossRef]

33. Buffet, C.; Wassermann, J.; Hecht, F.; Leenhardt, L.; Dupuy, C.; Groussin, L.; Lussey-Lepoutre, C. Redifferentiation of RadioiodineRefractory Thyroid Cancers. Endocr. Relat. Cancer 2020, 27, R113-R132. [CrossRef] [PubMed]

34. Zhang, C.; Bo, C.; Guo, L.; Yu, P.; Miao, S.; Gu, X. Bcl2 and Hsa-Mir-181a-5p Are Potential Biomarkers Associated with Papillary Thyroid Cancer Based on Bioinformatics Analysis. World J. Surg. Oncol. 2019, 17, 221. [CrossRef]

35. Cong, D.; He, M.; Chen, S.; Liu, X.; Liu, X.; Sun, H. Expression Profiles of Pivotal Micrornas and Targets in Thyroid Papillary Carcinoma: An Analysis of the Cancer Genome Atlas. Onco Targets Ther. 2015, 8, 2271-2277.

36. Celakovsky, P.; Kovarikova, H.; Chrobok, V.; Mejzlik, J.; Laco, J.; Vosmikova, H.; Chmelarova, M.; Ryska, A. Microrna Deregulation in Papillary Thyroid Cancer and Its Relationship with Braf V600e Mutation. In Vivo 2021, 35, 319-323. [CrossRef]

37. Sun, Y.; Shuang, Y.; Yuanyuan, L.; Fen, W.; Yujie, L.; Haipeng, X. Expression of Mirnas in Papillary Thyroid Carcinomas Is Associated with Braf Mutation and Clinicopathological Features in Chinese Patients. Int. J. Endocrinol. 2013, 5, 675-681.

38. Chmielik, E.; Rusinek, D.; Oczko-Wojciechowska, M.; Jarzab, M.; Krajewska, J.; Czarniecka, A.; Jarzab, B. Heterogeneity of Thyroid Cancer. Pathobiology 2018, 85, 117-129. [CrossRef] [PubMed]

39. Dai, Y.; Zhou, X. Computational Methods for the Identification of Microrna Targets. Open Access Bioinform. 2010, 2, $29-39$.

40. Chen, L.; Heikkinen, L.; Wang, C.; Yang, Y.; Sun, H.; Wong, G. Trends in the Development of Mirna Bioinformatics Tools. Brief. Bioinform. 2019, 20, 1836-1852. [CrossRef]

41. Lewis, B.P.; Shih, I.H.; Jones-Rhoades, M.W.; Bartel, D.P.; Burge, C.B. Prediction of Mammalian Microrna Targets. Cell 2003, 115, 787-798. [CrossRef]

42. Chi, S.W.; Hannon, G.J.; Darnell, R.B. An Alternative Mode of Microrna Target Recognition. Nat. Struct. Mol. Biol. 2012, 19, 321-327. [CrossRef]

43. Chandradoss, S.D.; Schirle, N.T.; Szczepaniak, M.; MacRae, I.J.; Joo, C. A Dynamic Search Process Underlies Microrna Targeting. Cell 2015, 162, 96-107. [CrossRef] [PubMed]

44. Wee, L.M.; Flores-Jasso, C.F.; Salomon, W.E.; Zamore, D.P. Argonaute Divides Its Rna Guide into Domains with Distinct Functions and Rna-Binding Properties. Cell 2012, 151, 1055-1067. [CrossRef]

45. Jin, Y.; Chen, Z.; Liu, X.; Zhou, X. Evaluating the Microrna Targeting Sites by Luciferase Reporter Gene Assay. Methods Mol. Biol. 2013, 936, 117-127.

46. Eichhorn, S.W.; Guo, H.; McGeary, S.E.; Rodriguez-Mias, R.A.; Shin, C.; Baek, D.; Hsu, S.H.; Ghoshal, K.; Villén, J.; Bartel, D.P. Mrna Destabilization Is the Dominant Effect of Mammalian Micrornas by the Time Substantial Repression Ensues. Mol. Cell 2014, 56, 104-115. [CrossRef]

47. Bartel, D.P. Metazoan Micrornas. Cell 2018, 173, 20-51. [CrossRef]

48. Fong, P. Apical Iodide Efflux in Thyroid. Vitam Horm. 2015, 98, 33-62.

49. Loeb, G.B.; Khan, A.A.; Canner, D.; Hiatt, J.B.; Shendure, J.; Darnell, R.B.; Leslie, C.S.; Rudensky, A.Y. Transcriptome-Wide Mir-155 Binding Map Reveals Widespread Noncanonical Microrna Targeting. Mol. Cell 2012, 48, 760-770. [CrossRef] [PubMed]

50. Wojcicka, A.; Swierniak, M.; Kornasiewicz, O.; Gierlikowski, W.; Maciag, M.; Kolanowska, M.; Kotlarek, M.; Gornicka, B.; Koperski, L.; Niewinski, G.; et al. Next Generation Sequencing Reveals Microrna Isoforms in Liver Cirrhosis and Hepatocellular Carcinoma. Int. J. Biochem. Cell Biol. 2014, 53, 208-217. [CrossRef] [PubMed]

51. Scientific \&-Educational Software. Clone Manager Professional Suite; Version 8; Scientific \&-Educational Software: Denver, CO, USA, 2005.

52. Wright, M.W.; Bruford, E.A. Naming 'Junk': Human Non-Protein Coding Rna (Ncrna) Gene Nomenclature. Hum. Genom. 2011, 5, 90-98. [CrossRef] [PubMed]

53. Ebert, M.S.; Neilson, J.R.; Shar, P.A.P. Microrna Sponges: Competitive Inhibitors of Small Rnas in Mammalian Cells. Nat. Methods 2007, 4, 721-726. [CrossRef] [PubMed]

54. Kogai, T.; Schultz, J.J.; Johnson, L.S.; Huang, M.; Brent, G.A. Retinoic Acid Induces Sodium/Iodide Symporter Gene Expression and Radioiodide Uptake in the Mcf-7 Breast Cancer Cell Line. Proc. Natl. Acad. Sci. USA 2000, 97, 8519-8524. [CrossRef] [PubMed]

55. Unterholzner, S.; Willhauck, M.J.; Cengic, N.; Schütz, M.; Göke, B.; Morris, J.C.; Spitzweg, C. Dexamethasone Stimulation of Retinoic Acid-Induced Sodium Iodide Symporter Expression and Cytotoxicity of 131-I in Breast Cancer Cells. J. Clin. Endocrinol. Metab. 2006, 91, 69-78. [CrossRef] [PubMed] 
56. Lin, X. Regulation of Sodium Iodide Symporter Expression/Function and Tissue-Targeted Gene Transfer of Sodium Iodide Symporter; The Ohio State University: Ohio, OH, USA, 2003.

57. GraphPad Software. Graphpad Prism; Version 5.03; GraphPad Software: La Jolla, CA, USA, 2009. 